\title{
COMPETÊNCIAS PROFISSIONAIS PARA ENFERMEIROS HOSPITALARES: UMA ANÁLISE DOCUMENTAL
}

\section{PROFESSIONAL COMPETENCIES FOR HOSPITAL NURSES: A DOCUMENTARY ANALYSIS}

\section{COMPETENCIAS PROFESIONALES PARA ENFERMEROS HOSPITALES: UN ANÁLISIS DOCUMENTAL}

\author{
Laura Adrian Leal ${ }^{1}$, Mirelle Inácio Soares ${ }^{2}$, Beatriz Regina da Silva ${ }^{3}$, Lana Joscasta de Souza Brito ${ }^{4}$, Andrea Bernardes ${ }^{5}$, Silvia Helena
} Henriques ${ }^{6}$.

\begin{abstract}
RESUMO
Objetivo: Analisar as competências profissionais requeridas para a atuação do enfermeiro hospitalar e aquelas implementadas durante a sua formação acadêmica. Método: Estudo documental, qualitativo, tendo como cenário uma instituição hospitalar pública e uma instituição de ensino superior, sendo fontes de evidências documentos legais das referidas instituições, os dados coletados de outubro de 2016 a janeiro de 2017. Foi utilizada a análise temática indutiva dos dados. Resultados: Permitiram identificar competências clínicas, como postura profissional e habilidades técnicas e gerenciais, como liderança e comunicação, em ambos os documentos, sendo algumas implementadas na formação acadêmica, porém não exigidas pela organização hospitalar, outras requeridas apenas pelo hospital e não desenvolvidas na formação acadêmica e, finalmente, algumas presentes nas duas instituições. Conclusões: Evidenciaram-se similaridades entre o requerido em uma instituição hospitalar e o ensinado na graduação, porém há a necessidade de centros formadores e gestores quanto a implementar estratégias para o desenvolvimento de competências clinicas e gerenciais.
\end{abstract}

Descritores: Enfermeiros; Competência Profissional; Educação Superior; Hospitais; Estratégias.

\begin{abstract}
Objective: To analyze the professional competencies required for the performance of hospital nurses and those implemented during their academic training. Method: Documentary-qualitative study; the scenarios were a public hospital institution and a higher education institution. The legal documents of those institutions were used as sources of evidence, whose data was collected from October 2016 to January 2017. Thematic inductive analysis was applied to the data. Results: The study allowed identifying clinical competencies such as professional attitude and technical and managerial competencies such as leadership and communication in both documents. Some competencies were implemented in academic training, but not required by the hospital organization; others, however, were required only by the hospital and not developed during training. Finally, some competencies were present in both institutions. Conclusions: Similarities were evidenced between the competencies required in the hospital and those taught in academic training. Nevertheless, there is a need for training centers and managers to implement strategies for the development of clinical and managerial competencies.
\end{abstract}

Descriptors: Nurses; Professional Competence; College education; Hospitals; Strategies.

\section{RESUMEN}

Objetivo: analizar las competencias profesionales requeridas para la actuación del enfermero hospitalario y aquellas implementadas durante su formación académica. Método: estudio documental, cualitativo, siendo los escenarios, una institución hospitalaria pública y una institución de enseñanza superior, teniendo como fuentes de evidencias documentos legales de dichas instituciones, siendo los datos recolectados de octubre de 2016 a enero de 2017. Se utilizó análisis temático inductivo de los datos. Resultados: permitieron identificar competencias clínicas, como postura profesional y habilidades técnicas, y gerenciales como liderazgo y comunicación, en ambos documentos, siendo algunas implementadas en la formación académica, pero no exigidas por la organización hospitalaria, otras requeridas sólo por el hospital y no desarrolladas en la formación académica y finalmente algunas presentes en las dos instituciones. Conclusiones: se evidenciaron semejanzas entre lo requerido en una institución hospitalaria y el enseñado en la graduación, pero hay la necesidad que centros formadores y gestores implementen estrategias para el desarrollo de competencias clínicas y gerenciales.

Descriptores: Enfermeros; Competencia Profesional; Educación Superior; Hospitales; Estrategias.

${ }^{1}$ Enfermeira. Doutoranda pela Universidade de São Paulo, Escola de Enfermagem de Ribeirão Preto. ${ }^{2}$ Enfermeira. Doutora pela Universidade de São Paulo da Escola de Enfermagem de Ribeirão Preto. ${ }^{3}$ Enfermeira. Doutoranda da Universidade de São Paulo da Escola de Enfermagem de Ribeirão Preto. ${ }^{4}$ Enfermeira. Mestranda da Universidade de São Paulo, Escola de Enfermagem de Ribeirão Preto. ${ }^{5}$ Enfermeira. Professora Associada da Universidade de São Paulo, Escola de Enfermagem de Ribeirão Preto, Departamento de Enfermagem Geral e Especializada. ${ }^{6}$ Enfermeira. Professora Associada da Universidade de São Paulo, Escola de Enfermagem de Ribeirão Preto, Departamento de Enfermagem Geral e Especializada.

Como citar este artigo:

Leal LA, Soares MI, Silva BR, et al. Competências Profissionais para Enfermeiros Hospitalares: Uma Análise Documental. Revista de Enfermagem do Centro Oeste Mineiro. 2019;9: e3249. [Access___]; Available in:__. DOI: http://dx.doi.org/10.19175/recom.v9i0.3249 


\section{INTRODUÇÃO}

As transformações que ocorrem, no mundo do trabalho, decorrentes da inovação tecnológica e de suas formas de organização, vêm exigindo a implementação de modelos de formação profissional e de gestão da força de trabalho fundamentada em competências profissionais. No setor saúde, como consequência a essas mudanças, as instituições necessitam constantemente atualizar suas práticas, requerendo trabalhadores com perfil diferenciado e competências específicas à determinada tarefa, facilitando a adaptação às exigências do mercado do trabalho ${ }^{(1)}$, que não é diferente nas organizações hospitalares.

Nesse contexto, as competências profissionais representam um conjunto de conhecimentos, habilidades e atitudes que cada trabalhador possui e que correspondem ao referencial para a construção de seu desenvolvimento na empresa ${ }^{(2)}$.

A temática competência profissional não é recente, sendo abordada, nos últimos anos, na área da saúde e constitui motivo de preocupação de gestores de serviços, bem como de centros formadores na capacitação de seus profissionais. A esse respeito, as Diretrizes Curriculares Nacionais (DCN) instituíram aos cursos da área de saúde um perfil acadêmico e profissional que inclui as competências: Atenção à saúde. Tomada de decisão. Comunicação. Liderança. Administração e Gerenciamento e Educação Permanente ${ }^{(3)}$.

Especificamente na enfermagem, as DCN apontam as competências profissionais como aspectos fundamentais na conformação dos projetos pedagógicos dos cursos norteando a formação dos enfermeiros. Deve-se considerar que, no ambiente de cuidado, a gerência e a assistência se articulam em todos os momentos, assim, o ensino fundamentado em competências, tanto gerenciais quanto competências clínicas (estas relacionadas aos cuidados diretos) atua como estratégia, para as transformações ocorridas, em especial, aos serviços hospitalares ${ }^{(3)}$.

Assim, alguns pesquisadores já identificaram as competências requeridas ao enfermeiro hospitalar, identificando-as como competências clínicas, agrupadas em sete domínios: a função de ajuda; de ensino e treinamento; de diagnóstico e monitoramento; gerenciamento eficaz das situações de rápida mudança; administração e monitoramento dos regimes e das intervenções terapêuticas, bem como monitoramento e garantia de qualidade das práticas na área da saúde ${ }^{(4-5)}$.

Já as competências gerenciais podem ser atribuídas a habilidades intrínsecas ao gerenciamento em enfermagem, como: a tomada de decisão que corresponde à capacitação do futuro profissional, a fim de avaliar, sistematizar e decidir as condutas; comunicação para interagir com outros; liderança no trabalho em equipe multiprofissional e administração e gerenciamento da força de trabalho, dos recursos físicos e materiais e de informação. Ainda, autores pontuam que a formação de competências gerenciais dos enfermeiros deve acontecer desde a formação na graduação e de forma contínua nos serviços hospitalares ${ }^{(6)}$.

O hospital enquanto organização de saúde complexa tem sido afetado tanto pelas transformações do mercado de trabalho, quanto pela formação dos profissionais que nele atuam. O impacto tecnológico associado à inserção de saberes necessários ao exercício das diferentes profissões da saúde exige dos profissionais dessa área, sobretudo, dos de enfermagem, perfil adaptativo para que, ao assumir novos papéis quanto às exigências, mobilizem competências necessárias à práxis profissional ${ }^{(7)}$. Nesse sentido, a organização hospitalar, na tentativa de suprir suas necessidades, busca definir perfis de competências aos seus trabalhadores.

Nessa ótica, esperam-se competências aos enfermeiros recém-formados a fim de atuarem em assistência hospitalar: capacidade de comunicação efetiva e documentação; trabalho em equipe e multidisciplinar; conhecimento; capacidade de lidar com e liderar pessoas; supervisão; manuseio de informática e tecnologia, entre outras. Além disso, pesquisadores apontam para a necessidade de que programas e/ou disciplinas de enfermagem aprimorem competências profissionais, durante a graduação, para que sirvam de exemplo à aprendizagem e à prática futura ${ }^{(8)}$.

Desta forma, pode-se afirmar que as competências profissionais necessárias aos egressos de enfermagem podem ser, inicialmente adquiridas pelo aprendizado da graduação e de cursos/capacitações, como também se observa a necessidade de investimentos na formação do enfermeiro essenciais à sua prática profissional ${ }^{(9)}$.

Um dos pilares das competências dos enfermeiros na assistência, no entanto envolve a gerência do processo de trabalho. Assim, centros 
formadores em enfermagem têm o papel de preparar futuros enfermeiros ao desenvolvimento não só de competências clínicas que são aquelas ligadas à prática e à técnica de trabalho, mas também competências gerenciais, que devem ser aprimoradas, por meio de disciplinas teórico-práticas específicas, para esta área de atuação, pois, ao se inserirem em ambientes tão complexos de assistência como os hospitais, estejam preparados para enfrentar seu cotidiano de trabalho de forma efetiva de acordo com o que se espera pela organização.

Nesse sentido, este estudo apresenta os questionamentos: Quais competências clínicas e gerenciais são estabelecidas ao profissional enfermeiro em uma instituição hospitalar de ensino público? Que tipos de competências são oferecidas no ensino de graduação de uma Instituição de Ensino Superior (IES) pública, em particular, na área de gerenciamento em enfermagem hospitalar?

Acerca da relevância desse assunto, esta investigação deve propiciar para que gestores das instituições hospitalares repensem sobre as competências essenciais que possam balizar a prática profissional do enfermeiro. Ainda, possibilitará aos centros formadores em enfermagem a reflexão quanto a possíveis lacunas de conhecimentos, habilidades e atitudes em seus currículos e à necessidade do desenvolvimento de estratégias pedagógicas que favoreçam a aquisição de formação apropriada às necessidades das organizações com 0 aprimoramento de novas competências.

Este estudo teve o objetivo de analisar as competências profissionais requeridas para a atuação do enfermeiro hospitalar e aquelas implementadas durante a sua formação acadêmica.

\section{MÉTODOS}

Trata-se de um estudo do tipo exploratório, documental, retrospectivo, utilizando-se a abordagem qualitativa dos dados. O cenário do estudo foi uma IES e uma instituição hospitalar de um município do interior paulista. A IES é uma Faculdade Pública de Enfermagem que oferece dois tipos de Cursos: "Bacharelado" e "Bacharelado e Licenciatura". A instituição hospitalar pública é um hospital de ensino de nível IV, com maior densidade tecnológica, abrangendo $o$ atendimento a transplantes, o qual possui parceria com a IES elegida, oferecendo diversos campos de estágio aos discentes atuantes nele.
A pesquisa considerou duas fontes de evidências: os documentos legais da instituição hospitalar e os programas relativos às disciplinas dos cursos da IES selecionada, da área de administração em enfermagem hospitalar. Os dados foram coletados de outubro de 2016 a janeiro de 2017. Destaca-se que os documentos da instituição hospitalar se deram, mediante formulário preenchido pela pesquisadora e entregues ao departamento de Recursos Humanos dessa instituição. Os documentos selecionados foram os editais para os Concursos Públicos ao cargo de enfermeiro, nos últimos 10 anos, ou seja, dos processos seletivos ocorridos em 2007, 2011 e 2014, os quais eram os únicos registros em que constavam as competências profissionais requeridas para o cargo.

Já em relação à IES, foram selecionados os Programas das disciplinas da área de Administração em enfermagem hospitalar, oferecidos nos terceiro e quarto anos de graduação, que descrevem diversas competências, entre elas, clínicas e gerenciais que podem ser aprimoradas e utilizadas pelos discentes durante a imersão. Os programas foram obtidos via internet no próprio site da IES selecionada. Ressalta-se que foram selecionados os programas publicados no site, no ano de 2016, cuja versão era a mais atualizada da matriz curricular.

Para a análise dos dados, foi eleita a análise temática indutiva, a qual identifica, analisa e relata os padrões (temas) quanto aos dados; organiza e descreve seu conjunto de dados em detalhes. Por meio de sua liberdade teórica, a análise temática proporciona uma ferramenta de pesquisa útil e flexível que pode potencialmente fornecer um relato rico, detalhado e complexo ${ }^{(10)}$.

Este estudo foi desenvolvido, de acordo com a Resolução CNS 466/2012 e foi aprovado pelo Comitê de Ética em Pesquisa (CEP) da Instituição proponente, conforme ofício № 241/2016, CAAE 57129716.0.0000.5393.

\section{RESULTADOS E DISCUSSÃO}

A leitura e a análise dos documentos da instituição hospitalar elucidaram diversas competências clínicas e gerenciais requeridas para o enfermeiro, em seu processo de trabalho, as quais são consideradas competências essenciais para que ele desenvolva seu serviço de forma efetiva no âmbito hospitalar, conforme apresentado no Quadro 1. 
Quadro 1 - Quadro de síntese das competências gerenciais e clínicas dos editais de uma instituição hospitalar de ensino do interior paulista, Brasil, 2017.

\begin{tabular}{|c|c|c|}
\hline $\begin{array}{l}\text { Editais de uma Instituição } \\
\text { hospitalar de Ensino }\end{array}$ & Competências gerenciais & Competências Clinicas \\
\hline Edital 2007 & $\begin{array}{l}\text {-Gerenciamento de materiais, } \\
\text { pessoas e custo do ambiente } \\
\text { de internação. } \\
\text {-Supervisão de enfermagem. } \\
\text {-Educação permanente à } \\
\text { equipe de trabalho. }\end{array}$ & $\begin{array}{l}\text {-Admissão dos pacientes na unidade e orientá-los quanto aos } \\
\text { regulamentos da instituição. } \\
\text {-Realizar cuidados diretos com pacientes, realizando visitas } \\
\text { diárias, inteirando-se de suas necessidades. } \\
\text {-Conferir censo da unidade de internação; preparar e } \\
\text { acompanhar pacientes em exames especiais; registrar } \\
\text { ocorrências em serviço. } \\
\text {-Realizar procedimentos técnicos de enfermagem. } \\
\text {-Realizar registro de enfermagem de forma correta e precisa. } \\
\text {-Uso da ética e da política nos atendimentos. } \\
\text {-Realização do processo de enfermagem e da Sistematização } \\
\text { da Assistência. }\end{array}$ \\
\hline Edital 2011 & $\begin{array}{l}\text { Anteriores somados à: } \\
\text { Colaboração/participação no } \\
\text { desenvolvimento de pesquisas } \\
\text { científicas. }\end{array}$ & $\begin{array}{l}\text { Anteriores somados à: } \\
\text {-Receber e passar plantão adequadamente. }\end{array}$ \\
\hline Edital 2014 & $\begin{array}{l}\text { Anteriores somados à: } \\
\text {-Atualização profissional. }\end{array}$ & $\begin{array}{l}\text { Anteriores somados à: Execução de tarefas afins que sejam } \\
\text { designadas pela chefia da unidade. }\end{array}$ \\
\hline
\end{tabular}

Fonte: Elaborado pelas autoras.

Já a análise dos documentos referentes à IES se fundamentou, na seleção de Programas de quatro disciplinas do ano de 2016, que desenvolvem e abordam as competências gerenciais e clínicas, sendo duas teóricas e duas teórico-práticas, pertencentes à área de administração em enfermagem hospitalar, conforme se evidencia no Quadro 2.

Quadro 2 - Quadro de síntese das competências gerenciais e clínicas dos programas das disciplinas de cursos de graduação em enfermagem de uma IES Pública do interior paulista, Brasil, 2017.

\begin{tabular}{|l|l|l|}
\hline $\begin{array}{l}\text { Programas das disciplinas de Instituição } \\
\text { de Ensino Superior Pública }\end{array}$ & \multicolumn{1}{|c|}{ Competências gerenciais } & \multicolumn{1}{|c|}{ Competências Clinicas } \\
\hline $\begin{array}{l}\text { Disciplinas Teóricas: } \\
\text { Disciplina 1 (Bacharelado) } \\
\text { Disciplina 2 (Bacharelado e Licenciatura) }\end{array}$ & $\begin{array}{l}\text {-Comunicação. } \\
\text {-Liderança. } \\
\text {-Trabalho em equipe. } \\
\text {-Tomada de Decisão. }\end{array}$ & $\begin{array}{l}\text {-Aprendizagem dos saberes atitudinais como postura, } \\
\text { reflexão, atuação da assistência com ética e } \\
\text { empoderamento. }\end{array}$ \\
\hline $\begin{array}{l}\text { Disciplinas teórico-práticas: } \\
\text { Disciplina 3 (Bacharelado) } \\
\text { Disciplina 4 (Bacharelado e Licenciatura). }\end{array}$ & $\begin{array}{l}\text {-Supervisão e Liderança } \\
\text { em Enfermagem; } \\
\text {-Gerenciamento da unidade } \\
\text { de internação; } \\
\text {-Gerenciamento de recursos } \\
\text { materiais, pessoas e custo; } \\
\text {-Relações no Trabalho } \\
\text { e Ética. }\end{array}$ & $\begin{array}{l}\text { - Aprimoramento de habilidades para intervenções de } \\
\text { enfermagem. } \\
\text {-Desenvolvimento de registros de enfermagem. } \\
\text {-Desenvolvimento de atitude proativa para o } \\
\text { gerenciamento do cuidado de enfermagem. } \\
\text {-lnserção e integração do estudante no grupo de } \\
\text { trabalho. } \\
\text {-Demonstração de atitudes éticas no gerenciamento do } \\
\text { cuidado de enfermagem. } \\
\text {-Relacionamento terapêutico na abordagem com o } \\
\text { cliente e família e equipe. }\end{array}$ \\
\hline
\end{tabular}

Fonte: Elaborado pelas autoras.

As disciplinas teóricas foram identificadas como: "Disciplina 1", para o Curso de Bacharelado em enfermagem e "Disciplina 2", para o Curso de Bacharelado e Licenciatura em Enfermagem, ambas apresentam similaridades em seus conteúdos, perfazendo diferenças apenas no método de ensino e carga horária. As disciplinas teórico-práticas foram identificadas como "Disciplina 3", para o Curso de Bacharelado em Enfermagem e "Disciplina 4", para o Curso de 
Bacharelado e Licenciatura, ambas apresentam matrizes curriculares com o mesmo conteúdo e propostas de aprendizagem similares. Todas as disciplinas, de uma forma geral, focalizam o desenvolvimento das atividades dos graduandos para o futuro profissional enfermeiro, no ambiente hospitalar, voltadas ao gerenciamento do cuidado e da equipe, como também apontam para a articulação entre as atividades gerenciais e assistenciais, na prática do enfermeiro, bases indissociáveis que norteiam o trabalho desse profissional.

$\mathrm{Na}$ análise dos Programas das disciplinas, verificou-se que a proposta de ensino teórica ao Curso de Bacharelado com carga horária de 75 horas se concentrou, no desenvolvimento de atividades de dispersão, em que os estudantes identificaram a realidade da prática gerencial por discussões, em rodas de conversa e em períodos de concentração, que consistem na teorização da gerência em enfermagem, assim como os estudantes assumem papéis de coordenador e relator de atividades, favorecendo a vivência do trabalho em equipe.

Para o Curso de Bacharelado e Licenciatura, a única alteração é a carga horária, que é constituída por 60 horas, ou seja, 15 horas menos, quando comparado com o curso de Bacharelado. A proposta de ensino é semelhante à disciplina do Bacharelado e se fundamenta, por meio da pedagogia da problematização como estratégia de ensino-aprendizagem. Ambas as disciplinas adotam como avaliação a participação em discussões e realização de prova escrita.

No entanto as disciplinas teórico-práticas dos dois cursos apresentam carga horária de 120 horas, as quais instrumentalizam o discente, para a função gerencial do cuidado de enfermagem e da unidade de internação, reconhecendo-se como agente desse processo e coordenando o trabalho da equipe de enfermagem. Assim, elas têm como meta desenvolver competências clínicas, como o aprimoramento técnico, e gerenciais, como: planejamento, a tomada de decisão, a supervisão, a informatização e as relações de trabalho com vista à promoção da qualidade e da humanização do cuidado na perspectiva da clínica ampliada.

Considerando que o enfermeiro, no contexto hospitalar, apresenta um papel relevante à equipe de saúde, este estudo teve como foco as competências profissionais desse trabalhador. Nesse contexto, acredita-se que o desempenho do profissional esteja diretamente relacionado com a sua formação acadêmica e, nesse sentido, ela deve contemplar uma gama de competências, ou seja, conhecimentos, habilidades e atitudes necessários para responder às demandas de saúde atuais.

Ressalta-se que o futuro enfermeiro enquanto discente precisa estimular seu raciocínio crítico, pensando e repensando sobre a gestão de pessoas, ambiente e ações para o objetivo principal da sua profissão que é o cuidado a ser atingido ${ }^{(11)}$. Assim, a análise dos documentos permitiu verificar que algumas competências se correspondem, isto é, aquilo que é exigido na instituição hospitalar é abordado na IES. A esse respeito, têm-se as competências clínicas, tais como: o uso da ética ou postura nos atendimentos prestados; realização de cuidados diretos com pacientes em relação a procedimentos/técnicas e a aplicação do conhecimento teórico-prático.

No que se refere a competências clínicas comuns mencionadas, destacou-se a postura profissional, considerada como uma competência fundamental do enfermeiro, a que pesquisadores atribuem que é essencial para um profissional de enfermagem ter postura e empatia, ter foco no ambiente, assiduidade e flexibilidade no ambiente de trabalho ${ }^{(12)}$. Nessas perspectivas, também se destacam os procedimentos técnicos e cuidados diretos com os pacientes, como o exame físico apurado e as habilidades procedimentais específicas do enfermeiro, como competências imprescindíveis, para a excelência do cuidado de enfermagem, as quais, muitas vezes, são aprendidas na graduação e aperfeiçoadas com a prática de trabalho na experiência profissional.

No que diz respeito à essa premissa, constata-se que a experiência profissional insuficiente é um dos desafios mais percebidos por recém-formados de setores hospitalares ${ }^{(13)}$. Desse modo, cabe às IES refletir e proporcionar ambientes e estratégias de aprendizagem apropriadas para que 0 discente possa desenvolver maiores habilidades técnicas e chegar ao mercado com preparo suficiente para o cuidado do paciente.

Contudo a IES, além de preparar seus discentes tecnicamente, deve garantir que os conhecimentos teóricos transmitidos sejam incorporados e utilizados à prática de trabalho futuro, proporcionando-lhes um raciocínio clínico e pensamento crítico apurados, para as atividades de enfermagem, com fins de se 
garantir a excelência da qualidade do cuidado. Assim, os dados deste estudo evidenciaram a competência clínica "conhecimento teóricoprático" como essencial para fundamentar uma práxis profissional de qualidade.

Nesse sentido, uma das formas que garante que essa competência seja desenvolvida e aprimorada, no ambiente da graduação, é o seu desenvolvimento e aperfeiçoamento durante o estágio. A imersão no cenário da prática possibilita o desenvolvimento de habilidades técnicas e o aprimoramento dos conhecimentos construídos em bases teóricas. Destarte, para que o estágio cumpra com o seu papel, faz-se necessária a presença de um profissional da instituição com formação ou experiência profissional, na área de conhecimento desenvolvida, a fim de orientar e supervisionar o discente em campo ${ }^{(14)}$.

Observa-se que o supervisor de estágio desempenha uma atribuição extremamente importante, na formação profissional do discente, visto que será o principal e, na maioria das vezes, o primeiro responsável em compartilhar as experiências ao articular o saber e o fazer.

Outro grande grupo de competência identificada como essencial, para o cargo de enfermeiro em um hospital e ensinada na IES, foram as competências gerenciais, entre elas, o gerenciamento de pessoas, de materiais, de custo e supervisão. Elas se destacam como competências gerenciais vitais para o processo de trabalho ativo no ambiente hospitalar. Gerenciar pessoas e recursos materiais está associado às atividades de coordenação e organização das normas e rotinas do seu processo de trabalho. Em consonância com essa premissa, a Lei do Exercício Profissional da Enfermagem prevê que o enfermeiro deve administrar e gerenciar os serviços de enfermagem, bem como a sua equipe, sempre priorizando a qualidade dos serviços oferecidos $^{(15-16)}$. Portanto analisar e conhecer sua unidade como um todo e os recursos disponíveis, supervisionar a equipe, prover o racionamento e conter o desperdício faz-se crucial para a assistência.

Ademais, no âmbito hospitalar, o enfermeiro é o profissional responsável por organizar o processo de trabalho da equipe de enfermagem, tendo que orientar e conduzir as suas tarefas, dimensionar os recursos humanos para o trabalho e gerenciar conflitos. Além disso, tem sido requisitado aos enfermeiros articular o trabalho dos demais profissionais do setor, reorganizar suas práticas e políticas, para nortear suas tarefas, o que também se revela na função de um gestor de pessoas ${ }^{(17)}$.

Além desses fatores, evidenciou-se a presença da competência gerencial de supervisão em ambos os documentos da IES e organização hospitalar. Nesse contexto, pode-se afirmar que a supervisão emerge como um instrumento importante, para a qualificação e registro legal da assistência integral ao usuário, permitindo o monitoramento dos cuidados de enfermagem prestados pela equipe, os quais também beneficiam uma abordagem que respalda e documenta o exercício profissional, favorecendo, inclusive, o faturamento e auditoria em saúde ${ }^{(18)}$. Sobre isso, vale enfatizar que o desenvolvimento dessa competência é imprescindível à excelência da prática profissional e para a qualidade dos serviços de saúde, devendo ser estimulada desde o início da graduação e aprimorada no ambiente de trabalho.

No entanto a literatura afirma que a estrutura organizacional hospitalar, a política de recursos humanos e os objetivos da instituição, na prestação de cuidados, influenciam as práticas do enfermeiro e, por conseguinte, sua supervisão no processo de trabalho ${ }^{(19)}$. Nesse cenário, os enfermeiros precisam considerar a cultura e o sistema organizacional do serviço no qual trabalham, uma vez que é majoritariamente nesse âmbito que se vivenciam os problemas éticos ${ }^{(20)}$. Assim, cabe às IES preparar o futuro enfermeiro para a prática, como também é indispensável que $\mathrm{o}$ ambiente de trabalho hospitalar ofereça condições para que esse profissional possa aprimorar essa competência por meio de educação permanente.

Nesse contexto, analisando os documentos separadamente, comprovou-se que as instituições hospitalares requerem também outra competência clínica não descrita nos documentos analisados da IES, como a realização da Sistematização da Assistência de Enfermagem (SAE). Com relação às competências gerenciais, foi possível também destacar outras requeridas que não constam nas disciplinas, como: educação permanente; colaboração em pesquisas e a atualização profissional. Dessa forma, destaca-se que o fato de não estarem nos documentos das disciplinas examinados não significa que o conteúdo não esteja sendo abordado pela IES. Todavia instiga a realização de novas investigações que ampliem as fontes de evidências. 
A SAE, considerada competência essencial para o desempenho das atividades da assistência hospitalar, é pontuada como processo e ferramenta que qualifica e instrumentaliza o enfermeiro e, desde seu surgimento, tem sido percebida como uma necessidade permanente, para a melhora da qualidade da assistência prestada aos indivíduos, uma vez que sua utilização favorece a seleção de intervenções individualizadas, como também proporciona melhoria na comunicação do trabalho e compartilhamento de informações ${ }^{(11)}$. Há, portanto que se aprimorar a utilização da SAE, efetivamente, na gestão do cuidado, visto que alguns instrumentos que deveriam estar alicerçados à SAE, para a tomada de decisão, ainda não estão presentes ${ }^{(21)}$. Nesse contexto, a IES, ao estimular e aderir a aprendizagem da SAE aos estudantes de forma clara, objetiva e sistemática, favorece que estes futuros profissionais realizem seu trabalho de forma mais clara e efetiva.

Com relação às competências gerenciais, evidenciou-se que a educação permanente é a preocupação das organizações hospitalares, ao passo que requerem que o enfermeiro seja capaz de educar sua equipe, família e paciente. A competência de educação permanente é considerada estratégia organizacional, a fim de desenvolver competências nos enfermeiros; para tanto, os gestores das instituições de saúde devem incentivar, motivar o aprendizado e serem facilitadores pela busca constante de treinamento, capacitações e atualizações dos seus conhecimentos que extrapolem os modelos tradicionais focados para capacitações verticalizadas que estejam direcionadas a atender lacunas de conhecimento pontuais durante 0 exercício da profissão.

Portanto, ainda, ressalta-se que a educação permanente, quando favorecida na interação ensino-serviço, possibilita a adequação do ensino às condições reais encontradas no mundo do trabalho ${ }^{(22)}$.

Nessa perspectiva, percebe-se a importância das IES readequarem seus currículos para a abordagem, implantação e desenvolvimento de competências, assim como que as instituições hospitalares ofertem estratégias de identificação de lacunas da prática profissional, ao utilizarem de educação permanente aos seus trabalhadores, por meio de capacitação profissional, oferecimento de cursos, atualizações, colaborações e participação em pesquisas científicas, para, assim, garantir efetividade e qualidade aos serviços prestados.

Em contraponto, ao analisar os documentos, também foram verificadas, nos programas das disciplinas da IES, competências gerenciais as quais não estão descritas na instituição hospitalar, tais como: liderança; comunicação; trabalho em equipe e relacionamento interpessoal. Logo, com relação à competência de Liderança e a Tomada de Decisão, reflete-se que, embora não estejam descritas nos documentos da instituição hospitalar, salienta-se que as organizações esperam, implicitamente, que o enfermeiro seja capaz de liderar e conduzir sua equipe de forma ativa.

Ainda neste contexto, apesar de a competência de liderança estar presente nos documentos da IES, destaca-se a grande preocupação dos docentes de enfermagem com a formação de enfermeiros com habilidades para exercer a liderança, visto que a formação está distante do desenvolvimento de líderes. Nesse enfoque, os conhecimentos, as habilidades e as capacidades, para a liderança em enfermagem, podem e deveriam ser ensinadas nos cursos de bacharelado, a fim de preparar estudantes para papéis de líderes. Contudo mudar currículos não produz resposta imediata à formação dos graduados ou ao seu preparo para ambientes de cuidados específicos. A liderança, especificamente, requer educação e experiência adicional $^{(23)}$. Sendo assim, primordial que a instituição formadora, além de repassar o conteúdo teórico, utilize de estratégias fortificadoras, para proporcionar o desenvolvimento dessas competências ao estudante, como o uso de simulações e exercícios direcionados ao campo de prática.

Todavia outra competência destacada somente nos documentos da IES foi a comunicação. Nessa perspectiva, a comunicação pode ser considerada fundamental, para o cuidado em enfermagem e, por meio de linguagem verbal e não verbal, bem como pela utilização de técnicas efetivas de comunicação, o enfermeiro perceberá sinais, gestos e movimentos que expressam as verdadeiras necessidades dos usuários, proporcionando um compartilhar de ideias, pensamentos e sentimentos de maneira clara e objetiva ${ }^{(24)}$. Assim, o processo de comunicação é fator determinante, para o estabelecimento de uma equipe coesa, permitindo a integração entre seus 
participantes, para a promoção do cuidado terapêutico ao ser humano e à família, nas instituições de saúde, cabendo, assim, o aprimoramento dessa competência por parte das instituições empregadoras.

Igualmente a competência comunicativa, outra descrita apenas nos documentos da IES, é o relacionamento interpessoal e o trabalho em equipe. Apesar de não conter nos documentos da instituição hospitalar, as organizações de saúde, de um modo geral, esperam que as relações de trabalho consigam se desenvolver com harmonia para que o processo de ocupação ocorra com equilíbrio.

Desse modo, pesquisadores consideram que o trabalho em equipe e o relacionamento interpessoal relacionados a aspectos de confiança, respeito mútuo, reconhecimento do trabalho por parte da enfermeira a sua equipe e o estabelecimento de vínculos, tornam-se fatores cruciais para a qualidade da assistência ${ }^{(25)}$.

Desse modo, percebe-se que o mercado de trabalho a enfermeiros iniciantes pode se apresentar repleto de estresse e incertezas, ao mesmo tempo em que existe uma ansiedade por parte dos recém-formados em dar início às atividades profissionais, obrigando-os a superar o seu medo do desconhecido.

Alguns dos elementos atuam como facilitadores, na transição da vida acadêmica para a profissional, tal como a formação acadêmica elencada em bons ensinamentos teóricos, em vivência de estágios extracurriculares, posicionamento institucional de motivação ao desenvolvimento educacional dos discentes e o apoio por parte dos demais membros mais experientes da equipe de trabalho ${ }^{(26)}$.

Tal cenário faz com que seja notável uma reestruturação do ensino superior, a fim de aproximar e estimular a vivência dos graduandos às práticas reais do cotidiano do enfermeiro.

Por fim, considera-se que a ênfase na formação generalista e a ampliação das possibilidades de experiência prática, durante o curso de graduação em enfermagem, podem ser alternativas para atender à exigência de um perfil de enfermeiros com competências necessárias, para a realidade das organizações de saúde, em especial, ao hospital.

Dessa forma, pode-se afirmar que as competências requeridas na instituição hospitalar se assemelham, em alguns aspectos, àquelas ensinadas/desenvolvidas, em uma IES, demonstrando ainda a necessidade de revisar e incluir competências, tanto no ponto das organizações quanto nos ensinamentos das IES, com fins de preparar melhor estes profissionais para a prática efetiva.

\section{CONSIDERAÇÕES FINAIS}

Em um pêndulo de idas e vindas, os resultados permitiram identificar competências gerenciais e clínicas essenciais ao enfermeiro hospitalar, sendo as competências clínicas: o uso da ética ou postura; realização de cuidados diretos com pacientes quanto a procedimentos/técnicas; a aplicação do conhecimento teórico-prático e SAE. Já no grupo das competências gerenciais: liderança; comunicação; trabalho em equipe; relacionamento interpessoal; gerenciamento de pessoas, material e custo, entre outros.

No geral, verificou-se que a maioria das competências requeridas na instituição hospitalar se assemelham àquelas ensinadas na IES, conforme os programas das disciplinas observados, porém assevera-se que o enfermeiro é responsável por tomar decisões no âmbito do hospital e, por isso, necessita estar preparado. Nesse sentido, sua formação acadêmica pode contribuir, sobremaneira, às suas atitudes e ao enfrentamento de desafios do cotidiano do trabalho, principalmente, numa instituição tão complexa como o hospital.

Assim, centros formadores devem repensar estratégias pedagógicas que auxiliem este processo de aprendizagem, bem como a instituição hospitalar tem a responsabilidade de promover o crescimento desse profissional, ao implementar estratégias, para que dificuldades sejam amenizadas e se tenham profissionais mais capacitados.

No entanto esta pesquisa possui uma limitação pelo fato de as pesquisadoras terem selecionado documentos de uma única instituição hospitalar e uma única IES. Desse modo, para as pesquisas futuras, recomenda-se ampliar o estudo a outras instituições de ensino e organizações hospitalares, com vista à comparação e/ou generalização dos dados de forma a contribuir para identificar "gaps" e/ou lacunas, na formação dos profissionais enfermeiros, quanto às competências que devem ser desenvolvidas para o ambiente hospitalar.

Em suma, acredita-se que este estudo seja de grande relevância e contribui à reflexão dos enfermeiros, gestores e centros formadores, para que conheçam as competências necessárias aos 
profissionais enfermeiros, para atuação no hospital e que possam planejar estratégias pedagógicas e educativas que possibilitem desenvolver ou aprimorar competências nesses trabalhadores.

\section{REFERÊNCIAS}

1- Camelo SHH, Angerami ELS. Professional competence: The building of concepts and strategies developed by health services and implications for nursing. Texto Contexto-Enferm. 2013;22(2):552-60. DOI: 10.1590/S010407072013000200034

2- Correa GC. Definição e desenvolvimento de competências: Um paradigma no processo estratégico. Estud CEPE 2015;39(67):103-16. DOI: 10.17058/cepe.v0i41.6294

3- Brasil. Ministério da Educação. Resolução CNE/CES no 3, de 7 de novembro de 2001. Institui Diretrizes Curriculares Nacionais do Curso de Graduação em Enfermagem. Diário Oficial da União 2001;1:37

4- Benner P. From novice to expert: Excellence and power in clinical nursing practice. New Jersey: Prentice Hall; 2001.

5- Aued GK, Bernardino E, Peres AM, Lacerda MR, Dellaire C, Ribas EN. Clinical competences of nursing assistants: A strategy for people management. Rev Bras Enferm. 2016;69(1):142-9. DOI: $10.1590 / 0034-7167.2016690119 i$

6- Sade PMC, Peres AM, Wolff LDG. The formation of the managerial competencies of nurses: An integrative review. REOUL 2014;8(6):1739-45. DOI: 10.5205/reuol.587650610-1-SM.0806201438

7- Bernardino E, Felli VEA, Peres AM. Competências gerais para o gerenciamento em enfermagem nos hospitais. Cogitare Enferm. 2010;15(2):349-53. DOI: 10.5380/ce.v15i2.17875

8- Brown RA, Crookes PA. What are the 'necessary' skills for a newly graduating RN? Results of na Australian survey. BMC Nurs. 2016;15(1):23. DOI: 10.1186/s12912-016-0144-8

9- Colenci R, Berti HW. Professional development and entering the labor market: The perceptions of nursing graduates. Rev Esc Enferm USP 2012;46(1):158-62. DOI: 10.1590/S0080$\underline{62342012000100022}$

10- Braun V, Clarke V. Using thematic analysis in psychology. Qual Res Psychol. 2006;3(2):77-101. DOI: 10.1191/1478088706qp063oa

11- Thoferhn MA (Org). Enfermagem: Manual de gerenciamento. Porto Alegre: Moriá; 2016.
12- Viana MAS, Fortuna SM, Borges FA, Gatto Junior JR, Matumoto S, Clapis MJ. Analysis of attitudinal assessment in the education of midlevel nursing professionals. Rev Eletrônica Enferm. 2016; 18:1-10. DOI: 10.5216/ree.v18.41632

13- Moreira AJN, Sampaio CCG, Silva ML, Chevitarese L. Mundo do trabalho: Dificuldades e desafios enfrentados pelos enfermeiros recémadmitidos em unidades hospitalares. Rede Cuid Saúde 2016 [citado em 31 dez 2018]; 10(3):1-16. Disponível em: http://publicacoes.unigranrio.br/index.php/rcs/ar ticle/view/3966

14- Ferreira MN, Reis AC. Estágio Curricular Supervisionado: $O$ papel do supervisor na formação profissional do discente de Engenharia de Produção. Scientia Plena 2016;12(2):1-9. DOI: 10.14808/sci.plena.2016.023601

15- Lima SBS, Rabenschlag LA, Tonini TFF, Menezes FL, Lampert AN. Conflitos gerenciais e estratégias de resolução pelos enfermeiros gerentes. Rev Enferm UFSM 2014;2(4):419-28. DOI: $10.5902 / 2179769211888$

16- Lima RS, Lourenço EB, Rosado SR, Sanches RS, Fava SMCL, Dázio EM. Gerenciar unidade de internação hospitalar: $O$ que pensam os enfermeiros? Rev Enferm Cent-Oeste Min. 2016;6(2):2190-98.

DOI:

10.19175/recom.v6i2.1128

17- Wegner RS, Godoy LP, Godoy TP, Bueno WP, Pereira MS. Trabalho em equipe sob a ótica da percepção dos gestores e funcionários de uma empresa de serviços. Pretexto 2018;19(1):11-24 DOI: 10.21714/pretexto.v19i1.3089

18- Chaves LDP, Mininel VA, Silva JAM, Alves LR, Silva MF, Camelo SHH. Nursing supervision for care comprehensiveness. Rev Bras Enferm. 2017;70(5): 1106-11. DOI: 10.1590/0034-71672016-0491

19- Schneider DG, Ramos FR. Moral deliberation and nursing ethics cases: Elements of a methodological proposal. Nurs Ethics 2012;19(6):764-76. DOI: 10.1177/0969733011420096

20- Suzuki C, Ota K, Matsuda M. Informationsharing ethical dilemmas and decision-making for public health nurses in Japan. Nurs Ethics 2015;22(5):533-47. DOI: 10.1177/0969733014549879

21- Benedet AS, Gelbcke FL, Amante LN, Padilha MIS, Pires DP. Nursing process: Systematization of the nursing care instrument in the perception of 
nurses. J Res Fundam Care 2016;8(3):4780-88. DOI: $10.9789 / 2175-5361.2016 . v 8 i 3.4780-4788$ 22- Mello AL, Brito LJS, Terra MG, Camelo SH. Estratégia organizacional para o desenvolvimento de competências de enfermeiros: Possibilidades de educação permanente em saúde. Esc Anna Nery 2018;22(1):1-5. DOI: 10.1590/2177-9465ean-2017-0192

23- Joseph ML, Huber DL. Clinical leadership development and education for nurses: Prospects and opportunities. J Healthc Leadersh. 2015;7:5564. DOI: $10.2147 / \mathrm{JHL} . S 68071$

24- Borba AP, Santos BM, Puggina AC. Barreiras de comunicação nas relações enfermeiropaciente: Revisão integrativa. Rev Saúde. 2017 [citado em 31 dez 2018];11 (1/2);48-61. Disponível em: http://revistas.ung.br/index.php/saude/article/vi ew/2848/2205

25- Souza GC, Peduzzi M, Silva JAM, Carvalho BG. Teamwork in nursing: Restricted to nursing professionals or an interprofessional collaboration? Rev Esc Enferm USP 2016;50(4):642-9. DOI: $\quad$ 10.1590/S0080$\underline{623420160000500015}$

26- Oliveira WA. Enfermagem: Os desafios e dificuldades do início da carreira. REFACI 2017 [citado em 31 dez 2018]; 2(2):1-19. Disponível em:

http://revista.faciplac.edu.br/index.php/REFACl/a rticle/view/227

Note: Artigo financiado pela Coordenação de Aperfeiçoamento de Pessoal de Nível Superior - CAPES e foi resultado de uma Dissertação de Mestrado apresentada em 2017 na Escola de Enfermagem de Ribeirão Preto, da Universidade de São Paulo, Programa de Pós-Graduação em Enfermagem Fundamental.

Recebido em: 08/01/2019

Aprovado em: 19/06/2019

Endereço de correspondência:

Laura Andrian Leal

Street Arlindo Jose Ferreira, 1285.

CEP: 14040-902 - Ribeirão Preto/SP - Brasil

E- mail: lauraleal4@hotmail.com 